\title{
3D Transient Heat Transfer Simulation of Spray Cooling on Titanium Alloy Slab
}

\author{
Mohamed Elguerri ${ }^{1,2}$ \\ ${ }^{1}$ Department of Mechanical Engineering, Faculty of Applied Science, University of Tiaret, Algeria \\ ${ }^{2}$ Industrial Technologies Research Laboratory, University of Tiaret, Algeria
}

Corresponding Author Email: mohamed.elguerri@univ-tiaret.dz

https://doi.org/10.18280/ti-ijes.642-414

Received: 15 March 2020

Accepted: 12 May 2020

\section{Keywords:}

heat transfer, simulation, slab, spray cooling, titanium alloy, transient, treedimensional

\begin{abstract}
In production of metals, commonly performed at elevated temperature, an intensive cooling is accompanied by a large heat transfer with the surrounding medium. Such cooling modifies strongly the properties and the structure of the product. Knowledge of the temperature evolution in a material allows controlling its important parameters in order to improve its qualities and optimize his costs. The focus of this article is to simulate the heat transfer by conduction in a slab on Titanium alloy. The slab in thermal interaction with the surrounding midst of its all sides by convection and radiation is sprayed by water on his upper side which must cool to reach the saturation temperature of water. During the cooling process, the impact of water droplets on the slab is obtained by twin overlapping sprays with elliptical shapes. The simulation, based on numerical solving in three dimensions of nonlinear transient heat equation, is carried out the COMSOL Multiphysics software in order to reach a temperature distribution inside the slab. Results are presented in temperature variation form which occurring in the slab and of heat flux involved to evaluate the heat transfer rate.
\end{abstract}

\section{INTRODUCTION}

The use of simulation of physical phenomena in industrial processes is increasingly growing to enhance productivity with lower energy costs, reducing expenses and improving product quality. The main element contributing to the success of a simulation is the quality and accuracy of data and the proper selection and application of boundary conditions.

As specified by Gonzalez et al. [1], computer models are currently a powerful and reliable tool for the thermomechanical and metallurgical processes simulation from where their increasing use for technological windows to control the different processes in metallurgical industry, such as continuous casting, hot rolling, heat treatments, etc. They conclude, from the results of the analyzed cases, that the developed modeling system provides reliable engineering information for analysis of actual industrial facilities.

Komínek et al. [2] indicate that simulations are based on the well-known phenomenon of heat conduction which is described by differential equations. In order to solve these equations, it is necessary to know thermally dependent material properties such as mass density, thermal capacity, and thermal conductivity, initial and boundary conditions.

Water is commonly used in metallurgical and materials manufacturing operations to cool products at a prescribed rate or down to a given temperature. Li et al. [3] remind that in processes include casting, hot deformation processes, and heat-treatment processes, water can be imparted onto the surface of the product in a variety of ways including via jet, spray, and mist systems, and via agitated and stagnant pools. In most industrial metallurgical operations, the temperature of the component being cooled is significantly greater than the boiling point of water, and hence transient boiling water conditions are experienced.

Water-cooling plays an important role in extracting heat from both the mold and solidifying metal during the continuous casting of steel and aluminum alloys and is characterized by complex boiling phenomena, Sengupta et al. [4]. Heat extraction rates during water-cooling, which have strong dependence on the metal surface temperature, can rapidly change with time as the strand cools down.

The study of spray cooling by water on highly heated metallic slabs and looking for an understanding of heat transfer mechanisms during this process serves to collecting information and data for the best design of an effective cooling system. Although the literature deals a number of practical cases in heat transfer process at spray cooling, no clear image could be complete so far, even taking into account all parameters influencing the process. In addition, other overall heat transfer experiments are needed to investigate and explain the phenomenon at different spray settings.

The aim of this paper is to examine by simulation, the effect of heat transfer by spray cooling, on temperature distribution in a slab in titanium alloy and, on heat flow released from the slab during the cooling process which can be considered as a phenomenon of transient quenching. The slab is sprayed by water on its upper side and in interaction by convection and radiation with the environment of its other sides. The cooling aims to maintain the saturation temperature of water in all points of the upper face of slab. Throughout the cooling process, the shape of impact by twin jets is an overlapping of two elliptical shapes. The simulation is based on threedimensional (3D) nonlinear numerical solution of transient heat equation used by the software COMSOL Multiphysics v3.5 to get the expected temperature distribution inside the slab. 


\section{PROBLEM DESCRIPTION}

To cool hot metal surfaces, there are practically three interesting process: cooling by film, by spraying or by immersion. Whatever type of cooling achieved on the hot surface, if the temperature is over $600^{\circ} \mathrm{C}$, a stable vapor film is established. Once of said Leidenfrost temperature at the surface is not reached, the vapor film formed fails and there starts partial evaporation.

The physical problem consists to simulate the process of heat transfer in a solid slab for a period of time during its cooling by spraying water to determine the temperature distribution at any point of the solid in question, Elguerri [5]. The materials traditionally used in such studies are usually steel or iron, aluminum, copper or magnesium alloys. In our case we consider a material highly demanded in studies and researches nowadays, very specially, for its thermophysical, chemical and mechanical properties and is already taking a place in some industries such as aerospace and nuclear, in addition to household appliances and other applications, it is the titanium alloy.

The geometry of the considered slab is of prismatic shape with a rectangular cross section. Scope at a very high temperature exceeding $1500^{\circ} \mathrm{C}$ at the outlet of the metallurgical furnace and after primary and secondary cooling and by natural convection accompanied by radiation during its displacement by means of a conveyor to a spray cooling section, the temperature reaches $1104^{\circ} \mathrm{C}$. Therefore, it will constitute a forced cooling operation by water jet to the upper face of the slab while the other sides are simply left to interact with the surrounding environment. Accordingly, the spray process extracts heat intensively from the slab through its top surface. The other free faces lateral and lower, exchanges the heat simultaneously to the environment, lowering the temperature in the slab over time. The direction of heat transfer is mainly upwards.

The purpose of this study is to establish three-dimensional temperature distribution maps, $T(x, y, z, t)$, in the slab of dimensions $X \times Y \times Z=940 \times 30 \times 100 \mathrm{~mm}^{3}$ with transient mixed boundary conditions, defined later. The situation is similar to the production conditions of the continuous casting process, to those of the rolling process metals, those of the tempering process metallurgy and many other processes such as intensive cooling in nuclear power plants. The proposed study seeks to elucidate the influence of spray process overlapping on heat transfer during cooling.

In summary, the problem amounts to solving the nonlinear transient heat conduction equation without heat source and without moving, as shown:

$$
\frac{\partial}{\partial x}\left(\lambda \frac{\partial T}{\partial x}\right)+\frac{\partial}{\partial y}\left(\lambda \frac{\partial T}{\partial y}\right)+\frac{\partial}{\partial z}\left(\lambda \frac{\partial T}{\partial z}\right)=\rho C\left(\frac{\partial T}{\partial t}\right)
$$

where $\lambda, \rho$ and $C$ are functions of temperature $T$ and is a function of $x, y, z$ and $t$. Direct solution of this equation can be done relatively easily using a numerical technique, with knowledge the thermophysical material properties and boundary conditions, Kotrbáček et al. [6].

The dispersion of water spray underneath two identical nozzles having jets which overlapping, is determined by a maximum rate, computed by Mzad and Elguerri [7] of the operating conditions defined for: the angle of opening nozzle $30^{\circ}$, passage section flow $47.05 \mathrm{~mm}^{2}$, height nozzle-target 300 $\mathrm{mm}$ and spacing of nozzles $300 \mathrm{~mm}$ at pressure jets of $0.2 \mathrm{MPa}$. The dimensions of the sprayed slab depend on the product ranges adopted in manufacturing process. It is important to note that the slab is designed so that the jet covers the entire impact surface with some intervals at the edges. Obviously, the dispersion depends on the spray hydrodynamic parameters and nozzle geometry. The average value utilized in all these conditions of operating is about $112.23 \mathrm{~mm}^{3} \cdot \mathrm{s}^{-1} \cdot \mathrm{mm}^{-2}$.

\section{THERMOPHYSICAL PROPERTIES}

Titanium and its alloys are relatively new engineering materials that possess an exceptionally combination of properties. These materials are widely used in many industrial and commercial applications such as aerospace, nuclear, chemical, automotive, medical and sporting goods industries and in many corrosive environments because the titanium alloys have excellent properties such as a shock resistance, high specific strength, high temperature strength and exceptional corrosion resistance.

Titanium alloy "Ti6Al4V" is the most worldwide used for its thermal and corrosion high resistance and its mechanical strength. Some applications of this alloy are encountered, as example blades, discs, rings, airframes, fasteners, implants, etc. Its thermophysical properties are often presented in published articles such as that of Bao-Cheng et al. [8] and Zhang et al. [9] but at specific conditions of use. However, their values do not change much with the change of these conditions.

These properties depend on the temperature if the material is orthotropic and are defined in the useful engineering software's. For example, the materials database of COMSOL software.

At high temperatures, thermal conductivity coefficient of titanium alloy depends of temperature as in Eq. (2). The constant value for isotropic material of Ti6Al4V is given by $6.70 \mathrm{~W} \cdot \mathrm{m}^{-1} \cdot \mathrm{K}^{-1}$. When the material is annealed above $331 \mathrm{~K}$ with $5 \%$ error; data interpolated between 60 and $311 \mathrm{~K}$, Umezawa and Ishikawa [10], he is considered as an orthotropic material and his components are shown as follow:

$$
\lambda=f\left(\lambda_{x}, \lambda_{y}, \lambda_{z}\right)
$$

For an orthotropic material under specified conditions, the thermophysic propertys at high temperature of ortotropic titanium alloy are also depending on the temperature, but the reference value for a supposedly isotropic material are all constant. The knowing constant values of the specific heat, the density, the thermal conductivity and the heat transfer coefficient for the titanium alloy Ti6Al4V at high temperature are, respectively, in the order of $526.3 \mathrm{~J} \cdot \mathrm{kg}^{-1} \cdot \mathrm{K}^{-1}, 4430 \mathrm{~kg} \cdot \mathrm{m}^{-3}$ and $7,2 \mathrm{~W} \cdot \mathrm{m}^{-1} \cdot \mathrm{K}^{-1}$ and $210 \mathrm{~W} \cdot \mathrm{m}^{-2} \cdot \mathrm{K}^{-1}$.

Determination of the temperature distribution allows following its evolution and optimizes the heat transfer in the slab during the cooling process by spraying. This optimization provides the conditions that can contribute to improving the productivity and material quality of product, and other operating parameters of such process.

To achieve this goal, we will define the simulation parameters which will allow determining the cordinates and temperature desired versus time from any point of the slab of titanium alloy under specific conditions very similar to those of the industrial process. 


\section{SIMULATION}

The first step of the simulation is to prepare the field of solid slab defined by its size and grid scale considering the following Cartesian coordinates $x, y$ and $z$. As shown in figure 1 , the grid is at scale of $0.100 \mathrm{~mm}$ in the $x$ direction, $0.025 \mathrm{~mm}$ for $y$, and $0.015 \mathrm{~mm}$ for $z$ direction. The studied slab has the properties shown in Table 1.

Table 1. Thermophysical properties of working flow

\begin{tabular}{cccccc}
\hline Water property & $\lambda$ & $\boldsymbol{\rho}$ & $\boldsymbol{C}$ & $\boldsymbol{T}_{\text {sat }}$ & $\boldsymbol{T}_{\text {Leid }}$ \\
\hline Value & $607 \cdot 10^{-3}$ & 1000 & 4.18 & 100 & 230 \\
\hline
\end{tabular}

\subsection{Domain meshing}

The area of the slab is divided into smaller finite elements at characteristics summarized in Table 2. The mesh is automatically done by the code, and being fine and regular as shown in Figure 1. The slab material is an alloy of titaniumaluminum-vanadium (Ti6Al4V), from series UNS R56400, exits from the metallurgical furnace before reaching the position below the spray cooling device at completely solid state.

Table 2. Mesh statistics

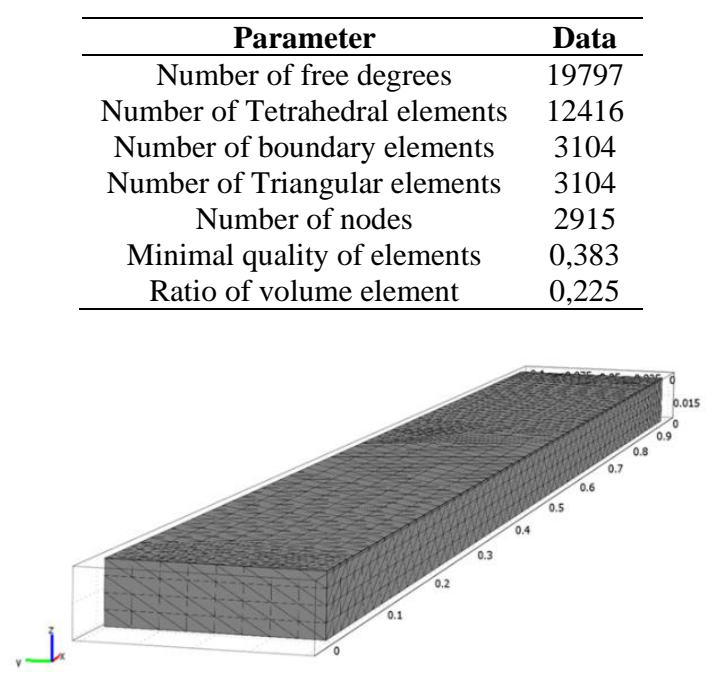

Figure 1. Global representation of meshing of the domain

This hot metal at a temperature of about $\sim 1104^{\circ} \mathrm{C}$ takes a horizontal static position then it is sprayed by a spray boom at two jets of sprays longitudinally overlapping according to the $\mathrm{x}$ direction. The water at controlled ambient temperature of $25^{\circ} \mathrm{C}$ is set to the hot surface to create a layer of water film boiling having a heat transfer coefficient, $h_{D}$, in addition to the radiation emitted by the hot slab and its convection with the surrounding air.

The problem is considered as typically thermal, because we neglect the mechanical aspect which considers the stresses of contact between the slab and the supports that carry it in the spot of the cooling. We have used the computer code COMSOL to solve the heat transfer problem by transient conduction in the slab.

Firstly, we define the mode of solving the problem, then; we adjust the axes and grid to draw the geometry of the slab. After, the material chosen for the study is selected and defined, thus the thermophysical properties were prescribed at the initial temperature for which the material is heated. The next step is to define the boundary conditions of the slab, then initialization and updating the solver to run the program and solving the transient problem.

\subsection{Boundary conditions}

The heat equation accepts two types of boundary conditions specified temperature and specified heat flux. The first is Dirichlet type and prescribe temperature at the border:

$$
T=T_{0}
$$

On the domain, while the second specifies a heat flux where:

$$
q_{0}^{\prime \prime}=n q^{\prime \prime}
$$

On the domain, where $\mathrm{q}^{\prime \prime}$ is the vector of total heat flux:

$$
q^{\prime \prime}=-\lambda \nabla T
$$

$\mathrm{n}$ is a normal vector to the boundary and $\mathrm{q} 0$ " is the heat flux, also normal to the border.

Note that when the heat transfer by convection is active, the boundary condition of heat flux is of mixed type, or Robin, rather than a boundary condition of pure Neumann, Taler and Duda [11] and Huiping et al. [12].

The heat flow $q_{0}$ " is normally a sum of contributions of the different heat transfer process. It is often convenient to divide the boundary condition of heat flow

$$
-n(\lambda \nabla \mathrm{T})=q^{\prime \prime}
$$

Initially, the temperature at any point of domain (uniform), represented by the function $T(x, y, z, t)$ is set at time $t=0 \mathrm{~s}$ which defines the initial condition $T(x, y, z, 0)=T_{0}(x, y, z)=T_{\text {init }}$ or $T_{0}$. This temperature is obtained from the melting point of Ti-6Al$4 \mathrm{~V}$ which is around $\sim 1104^{\circ} \mathrm{C}$, minus a temperature of about $\sim$ $500^{\circ} \mathrm{C}$ due to cooling by radiation and natural convection the slab at its outlet from the furnace to the cooling zone by spraying. The area of the slab is of parallelepiped form of six faces, each of which is imposed the boundary condition appropriate. It means that faces are: (1) front, (2) right side, (3) lower, (4) upper, (5) the left side and (6) back side. The boundary conditions applied in our problem are heat flow type specified. We have two types of flows imposed: the first to the upper surface and the second in other surfaces. For the boundary condition of the upper face (3) for $z=30 \mathrm{~mm}$, we meet the convection of boiling with phase change characterized by a water film boiling temperature of $100^{\circ} \mathrm{C}$, a convection of air and a radiation which are governed by the equation:

$$
\begin{gathered}
q_{0}^{\prime \prime}=q^{\prime \prime}{ }_{s p r}+q_{c o n v}^{\prime}+q^{\prime \prime a d} \\
-\left.\lambda(T) \frac{\partial T}{\partial z}\right|_{z=0,03}= \\
h_{D}\left(T-T_{b}\right)+h_{a}\left(T-T_{a m b}\right)+\sigma \varepsilon\left(T^{4}-T_{a m b}{ }^{4}\right)
\end{gathered}
$$

$h_{D}$ is the two-phase heat transfer coefficient obtained from previous hydrodynamic calculations (it is assumed uniform over all the sprayed area): 


$$
h_{D}=\frac{q^{\prime \prime} s p}{T-T_{b}}
$$

$q^{\prime \prime}{ }_{s p r}$ is the heat flow in the water-cooling spray and can be measured using the equation of Bratuta and Ivanowsky [13]:

$$
q_{s p r}=4.6 \cdot 10^{6} \cdot(\Delta P)^{0.1}\left[g_{\max }(x, y)\right]^{0.4}
$$

After using hydrodynamic results (Table 3) due to the use of equations and data cited before, the necessary results of the two-phase heat transfer coefficient $h_{D}$ grouped in this Table are obtained by considering nozzle exit area and overlap area. The slab emits radiation at ambient temperature to $25^{\circ} \mathrm{C}$ with nonlinear property exchange environment, knowing that $h_{a}$ is the coefficient of heat transfer by convection with air obtained from the following equation, Mzad and Tebbal [14]:

$$
h_{a}=0.046 \cdot T_{w}+6.8
$$

$\sigma=5.67 \cdot 10^{-8} \mathrm{Wm}^{-2} \cdot \mathrm{K}^{-4}$ and the emissivity $\varepsilon$ is calculated from the following equation Liscic et al. [15]:

$$
\begin{gathered}
h_{a}=0.046 T_{w}+6.8 \varepsilon(T)= \\
0.1536+1.8377 \cdot 10^{-4} \cdot\left(T_{0}-300\right)
\end{gathered}
$$

Table 3 Dispersion $\left(g_{\max }\right)$ and two-phase heat transfer coefficients $\left(h_{D}\right)$ according to geometrical characteristics of the nozzles for $\Delta P=0.2 \mathrm{MPa}$, Elguerri [5].

\begin{tabular}{ccccccc}
\hline Nozzle & $\boldsymbol{\varphi}$ & $\boldsymbol{S}$ & $\boldsymbol{g}_{\max \mathbf{1}}$ & $\boldsymbol{h}_{\boldsymbol{D} \mathbf{1}}$ & $\boldsymbol{g}_{\max \mathbf{2}}$ & $\boldsymbol{h}_{\boldsymbol{D} \mathbf{2}}$ \\
\hline $\mathrm{N}^{\circ} 1$ & 30 & 47.05 & 107.88 & 12795.79 & 112.23 & 12999.73 \\
\hline
\end{tabular}

Boundary conditions of sides: $x=0 \mathrm{~mm}$ at front, $x=940$ $\mathrm{mm}$ at rear, right side $y=0 \mathrm{~mm}$, left side $y=100 \mathrm{~mm}$ and $z=0$ $\mathrm{mm}$ at the bottom. The slab is cooled by natural convection, and emits radiation at ambient temperature to $25^{\circ} \mathrm{C}$ with nonlinear exchange property. In this case, the type of boundary conditions selected for these faces is of heat flux type, with:

$$
\begin{gathered}
q_{0}^{\prime \prime}=q_{\text {conv }}+q_{\text {rad }} \\
-\left.\lambda(T) \frac{\partial T}{\partial z}\right|_{z=0}=h_{a}\left(T-T_{a m b}\right)+\sigma \varepsilon\left(T^{4}-T_{a m b}{ }^{4}\right)
\end{gathered}
$$

Similarly, to the other faces:

$$
\begin{aligned}
& -\left.\lambda(T) \frac{\partial T}{\partial x}\right|_{x=0}=h_{c o n v}\left(T-T_{a m b}\right)+\sigma \varepsilon\left(T^{4}-T_{a m b}^{4}\right) \\
& -\left.\lambda(T) \frac{\partial T}{\partial x}\right|_{x=0,94}=h_{c o n v}\left(T-T_{a m b}\right)+\sigma \varepsilon\left(T^{4}-T_{a m b}^{4}\right) \\
& -\left.\lambda(T) \frac{\partial T}{\partial y}\right|_{y=0}=h_{c o n v}\left(T-T_{a m b}\right)+\sigma \varepsilon\left(T^{4}-T_{a m b}^{4}\right)
\end{aligned}
$$

$$
-\left.\lambda(T) \frac{\partial T}{\partial y}\right|_{y=0,1}=h_{c o n v}\left(T-T_{a m b}\right)+\sigma \varepsilon\left(T^{4}-T_{a m b}^{4}\right)
$$

In summary, the values of the necessary flux imposed on each face are shown in Table 4.

Table 4. Definition of the boundary conditions, Elguerri [5].

\begin{tabular}{cccc}
\hline \multirow{2}{*}{ Boundary } & \multirow{2}{*}{ Symbol } & \multicolumn{2}{c}{ Surface } \\
\cline { 3 - 4 } & & $\mathbf{1 - 3 / 5 - 6}$ & $\mathbf{4}$ \\
\hline Type & $h$ & 70.15 & 12795.79 \\
\hline Heat transfer coefficient & $h$ & 25.00 & 100.00 \\
\hline Extern temperature & $T_{i n f}$ & 25.00 & 25.00 \\
\hline Ambient temperature & $T_{a m b}$ &
\end{tabular}

\section{RESULTS AND DISCUSSIONS}

The results obtained by this simulation were selected and organized by category to allow analyze the temperature distributions in different situations.

The problem treated consist to the simulation based on the resolution of the non-linear heat equation in transient regime of the heat transfer process during the water spray dispersed under nozzles in two jets which overlap on a metal slab heated at high temperature.

The results were used to follow instantaneously the process from beginning to end at any moment and assess the evolution of the temperature in the body of the slab and therefore other parameters associated with it, such as heat flow, heat transfer coefficient and thermophysical properties of the material. The classification and organization of results by category is to facilitate the monitoring of interpretations that we try to make them clearer and more objective.

The first category illustrated in Figure 2 to Figure 5, shows the spatial evolution of cooling in the slab. Visibly, we see that the cooling carried out in earliest times in uniform layers of iso-temperatures, continuously progressing downwards. Secondly, this form changes due to interaction with the environment outside of the spray cooling zone, the first is with natural convection and radiation of the lower and sides and the second is by forced convection with phase change and radiation from the upper face. This causes a strong cooling in the vicinity of all sides except the top side. This cooling modifies the layers shape, initially rectangular, with forms rounded near the edges and more accentuated towards the middle as shown in Figure 4 to Figure 5 from $50 \mathrm{~s}$.

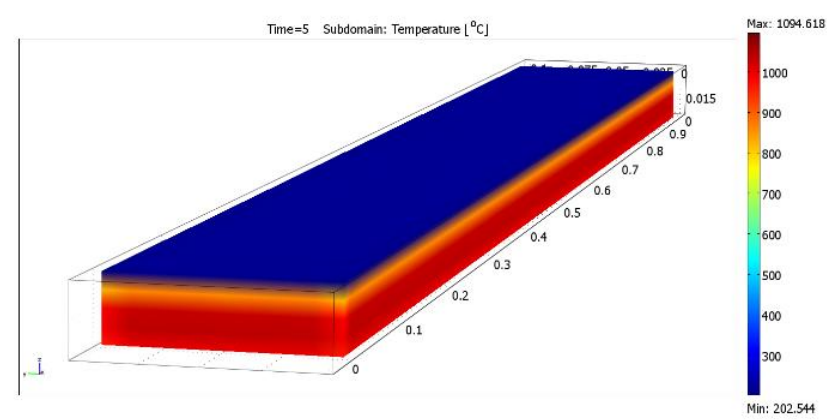

a) 


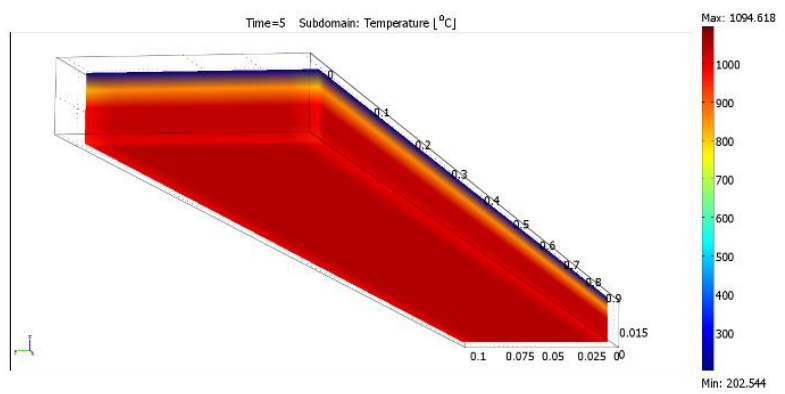

b)

Figure 2. Launch of the simulation, temperature distribution views after 5 seconds: $\boldsymbol{a}$ ) top, $\boldsymbol{b}$ ) bottom

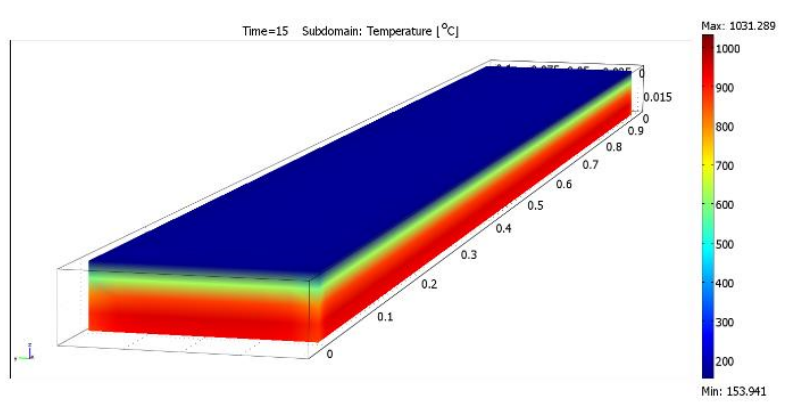

a)

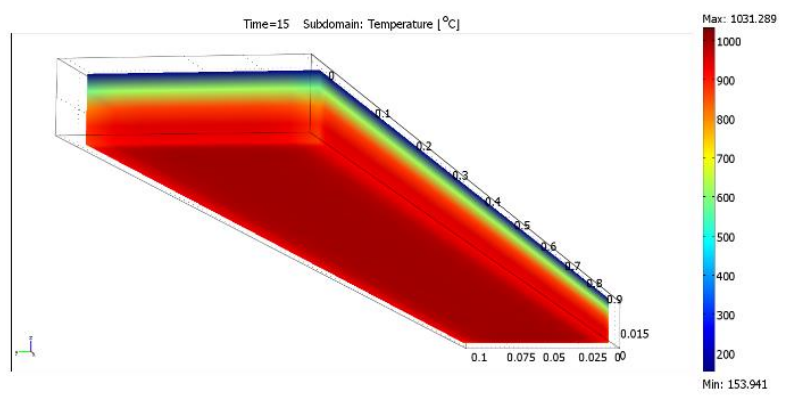

b)

Figure 3. Simulation in progress, temperature distribution views after $15 \mathrm{~s}: \boldsymbol{a})$ top, $\boldsymbol{b}$ ) bottom

On the temperature scale of Figure 3 to Figure 5, it is important to note that the temperature drops from 1031, 289 to $188.071^{\circ} \mathrm{C}$ in the underside slab but she is uniform in the vicinity of the upper side with $100^{\circ} \mathrm{C}$.

Overall, it can distinguish two phases of cooling of the surface of the slab. The first corresponds to a sudden and rapid fall in surface temperature that takes place during a very short time of a few seconds, about seven seconds, after which the temperature fall recorded is from 1104 to $200^{\circ} \mathrm{C}$. Then the second phase, where the process is strongly damped by a slow and fairly regular fall of the temperature, resulting in the steady state.

Periods of time were selected to examine the evolution of the temperature during the cooling process. These times were $5 \mathrm{~s}, 15 \mathrm{~s}, 100 \mathrm{~s}$ and the final time for which the top surface and side of jets reached $100^{\circ} \mathrm{C}(t=221 \mathrm{~s})$.

Sectional views are presented in Figure 6 and Figure 7 in different arrangements, horizontals, with upper, lower and medium planes, verticals, with longitudinal planes and vertical with several transverse planes.

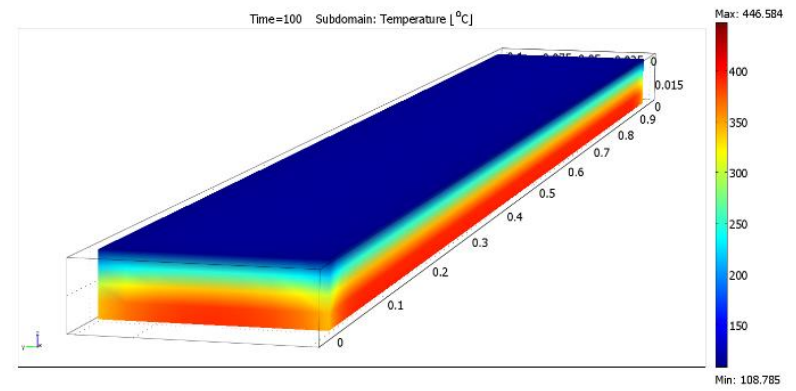

a)

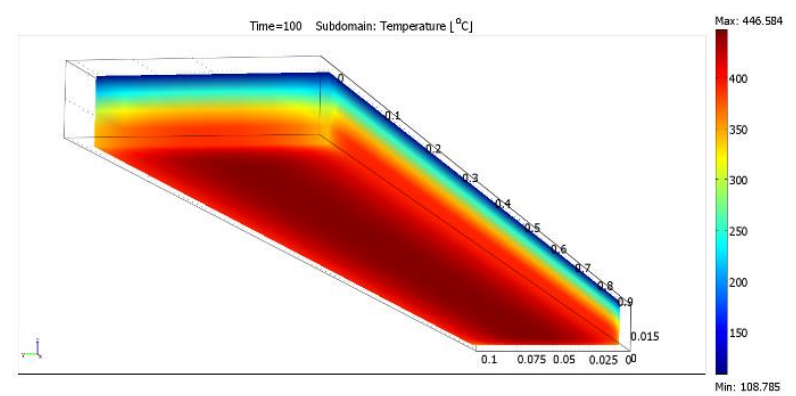

b)

Figure 4. Temperature distribution views after $100 \mathrm{~s}$ : a) top, $\boldsymbol{b}$ ) bottom

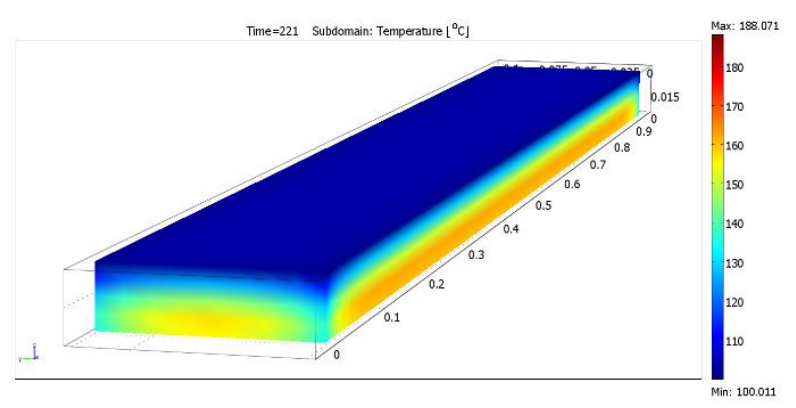

a)

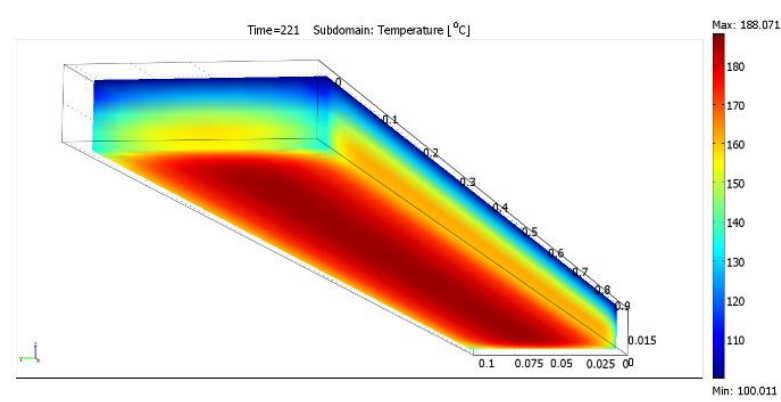

b)

Figure 5. End of simulation, cooling of the surface to $100^{\circ} \mathrm{C}$ after $221 \mathrm{~s}: \boldsymbol{a}$ ) top view, $\boldsymbol{b}$ ) bottom view

These figures show the spatio-temporal shape of the distribution of the temperature in different planes which indicate that this distribution is not the same from one plan to another according to $z$, similarly, it is not also the same at planes along $y$, which are along the distributions $y$ symmetrically with the central plane $y=50 \mathrm{~mm}$ and different distributions according to planes $x$ with symmetry with respect to center of $x$. 


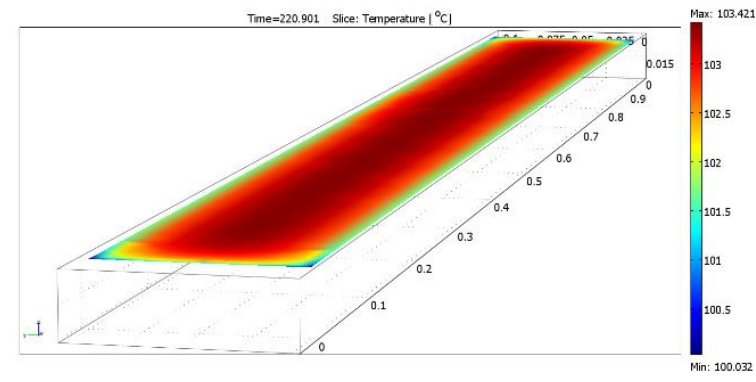

a)

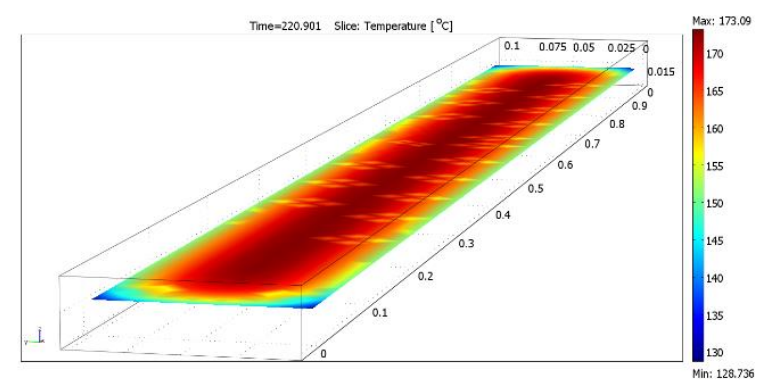

b)

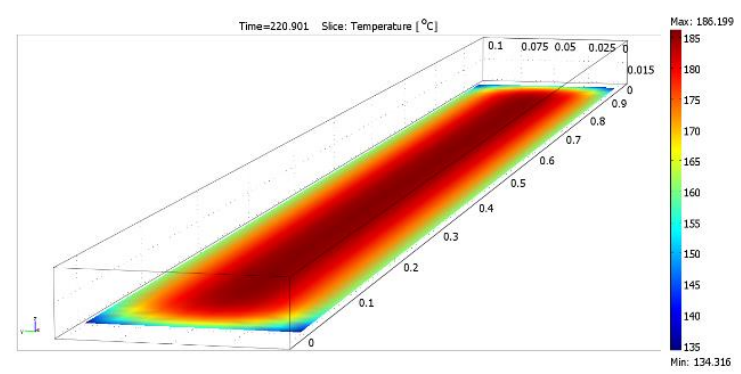

c)

Figure 6. Horizontal sectional cross sections, longitudinally viewed: $\boldsymbol{a}$ ) top, $\boldsymbol{b}$ ) medium and $\boldsymbol{c}$ ) bottom

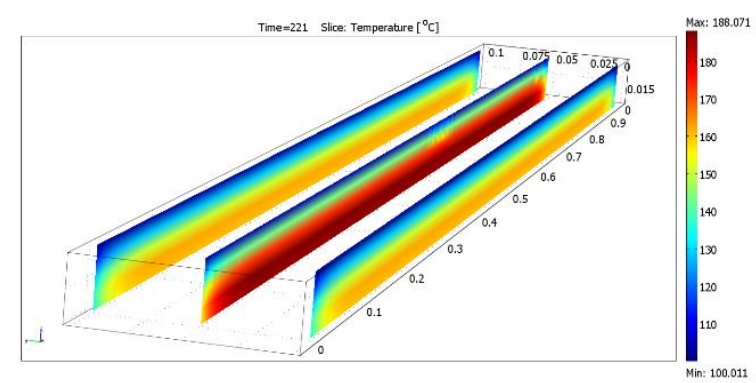

a)

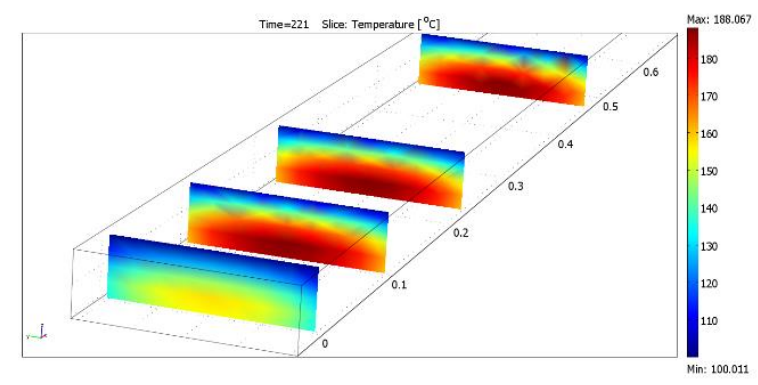

b)

Figure 7. Cross section views: $\boldsymbol{a}$ ) Longitudinal of two extreme plans and a mid-plane, $\boldsymbol{b}$ ) Transversal on several planes
Figure 8 shows three-dimensional iso-surfaces in the form of envelopes, distributed in the volume of the slab, concentrated inwardly and downwardly. This representation is useful in showing the manner according to which the temperature evolves within the body of the slab.

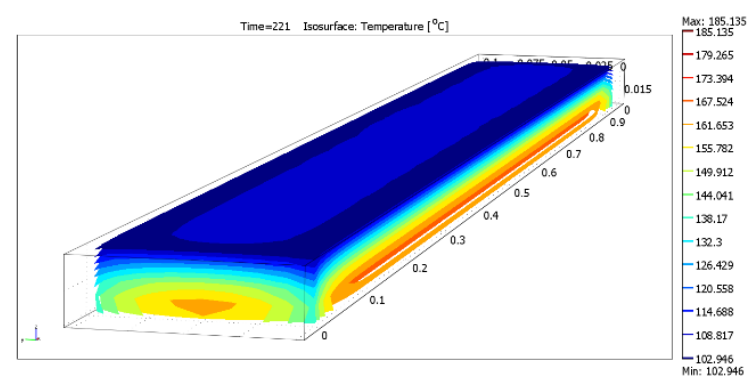

a)

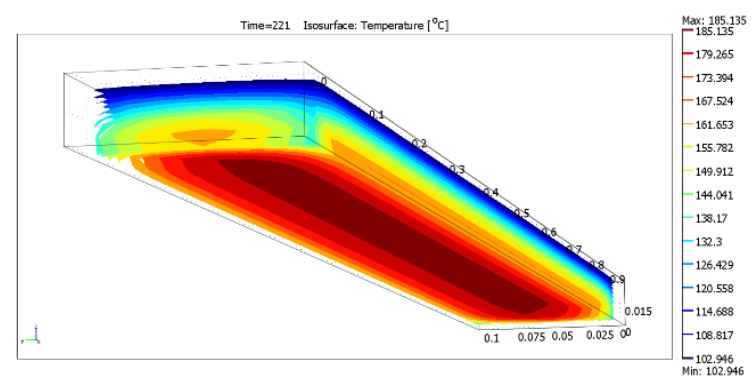

b)

Figure 8. Temperatures viewed in iso-surfaces: $\boldsymbol{a}$ ) of top, $\boldsymbol{b}$ ) of below

Figure 9 present the temperatures distribution inside the slab from the center points at coordinates $x=470 \mathrm{~mm}, y=50 \mathrm{~mm}$ and by step of $1 \mathrm{~mm}$ for $z$, from the down to top. Manifestly, as it is shown three groups of curves representing gradually the cooling of slab.

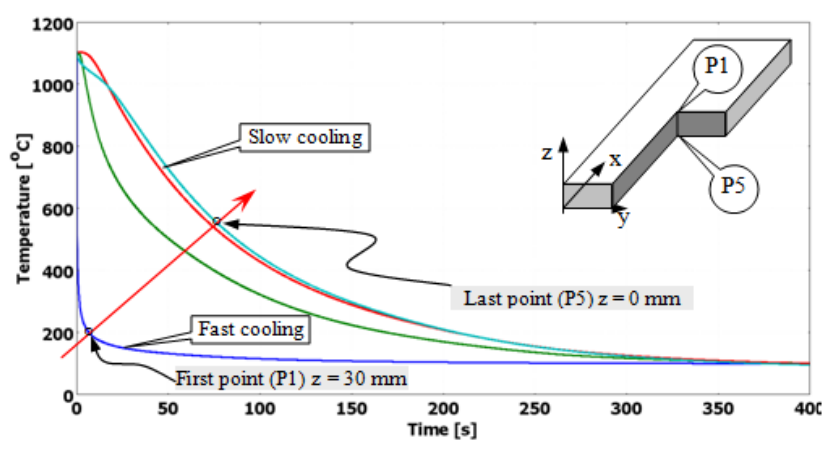

Figure 9. Temperatures distribution of center points at coordinates: $x=470 \mathrm{~mm}, y=50 \mathrm{~mm}$ and $z=0$ to $30 \mathrm{~mm}$ by step of $10 \mathrm{~mm}$, from the down to top

The curves in Figure $10(a)$ to $(c)$ begin to break away one of other by subsidence downwardly from $10 \mathrm{~mm}$ as illustrated by arrow indicated for each curves group. Although the points are equidistant, curves detachment is accentuated to reaching the lowest curve at the bottom face corresponding to the lower temperature (Figure $10(c)$ ).

By contrasting our results of simulation with those of numerical FEM and analytical computation presented by Huiping et al. [12], it is clearly seen that our results are 
consistent with the others and seem to be very similar. This approach is quite sufficient for the validation of our results. To approve the results, we have compared them with those of Deiters and Mudawar [16] and Chen et al. [17]. We found that they have the same shape as those of figures 9 and 10 . In other hand, the cooling curves that we have obtained seem to be similar to those of Frkáňová and Lapin [18] which have use ANSYS software for the simulation of cooling rates, calculated for several different distances from the watercooled surface.

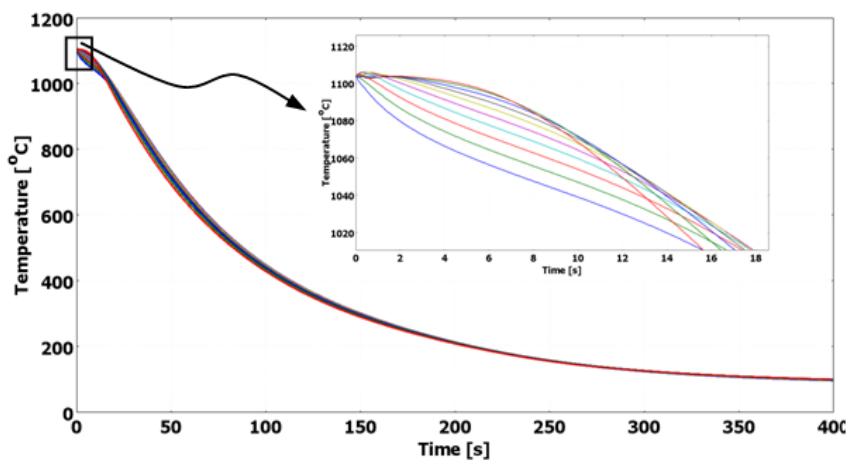

a)

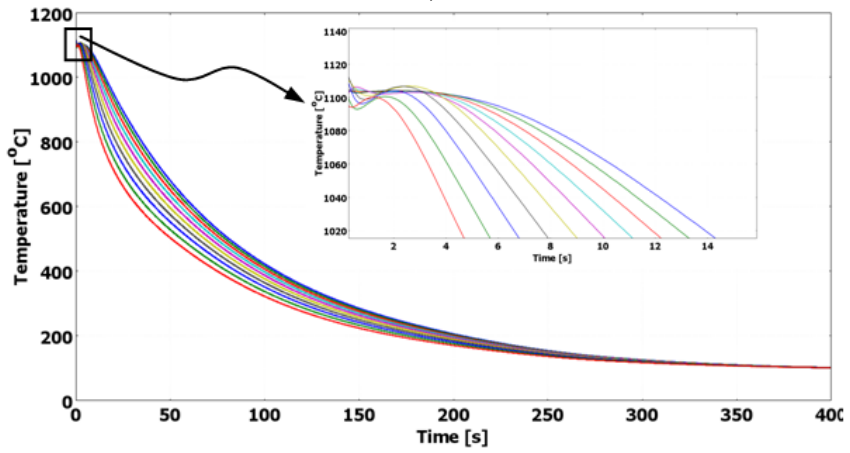

b)

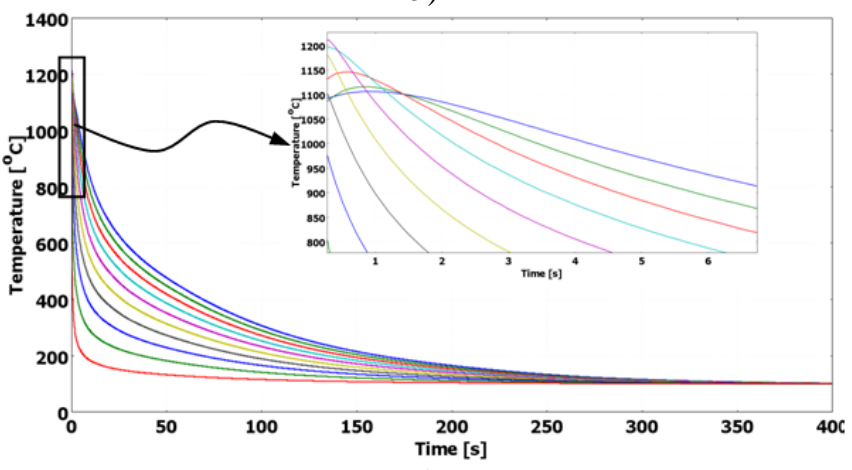

c)

Figure 10. Temperatures distribution of center points at coordinates $x=470 \mathrm{~mm}, y=50 \mathrm{~mm}$ by step of $1 \mathrm{~mm}$, from the down to top: $\boldsymbol{a}) z=1$ to $10 \mathrm{~mm}, \boldsymbol{b}) z=10$ to $20 \mathrm{~mm}, \boldsymbol{c}$ ) $z=$ 20 to $30 \mathrm{~mm}$

Finally, the resulting curve (Figure 11) reveals three distinct heat transfer regimes in a typically spray cooling curves: Single phase forced convection region where heat transfer coefficient is low. Two phase boiling/evaporation region where heat transfer coefficient is much higher due to the activation of additional heat transfer mechanisms at higher superheats. Two phase-to-CHF transition region where heat transfer coefficient starts to decrease with the inception of heater dry-out.

Two straight lines marked on the cooling curve represent two of the heat transfer regimes; single phase forced convection, region (A), and two phase boiling-evaporation, region (B). The curve gives evolution of heat flux for some specified points of the upper surface in function of the difference in saturation temperature in a logarithmic scale. It is shown on this figure a critical heat flux $C H F=3.89 \cdot 10^{6}$ W. $\mathrm{m}^{-2}$ about a temperature difference of saturation $\Delta T_{\text {sat }}=$ $415.53^{\circ} \mathrm{C}$ for the point $(\mathrm{P} 1), 4.269 \cdot 10^{6} \mathrm{~W} . \mathrm{m}^{-2}$ for $537.68^{\circ} \mathrm{C}$ for (P3), $4.207 \cdot 10^{6} \mathrm{~W} \cdot \mathrm{m}^{-2}$ for $448.59^{\circ} \mathrm{C}$ for $(\mathrm{P} 2)$ and $3.751 \cdot 10^{6}$ $\mathrm{W} . \mathrm{m}^{-2}$ for $448.92^{\circ} \mathrm{C}$ for $(\mathrm{P} 4)$.

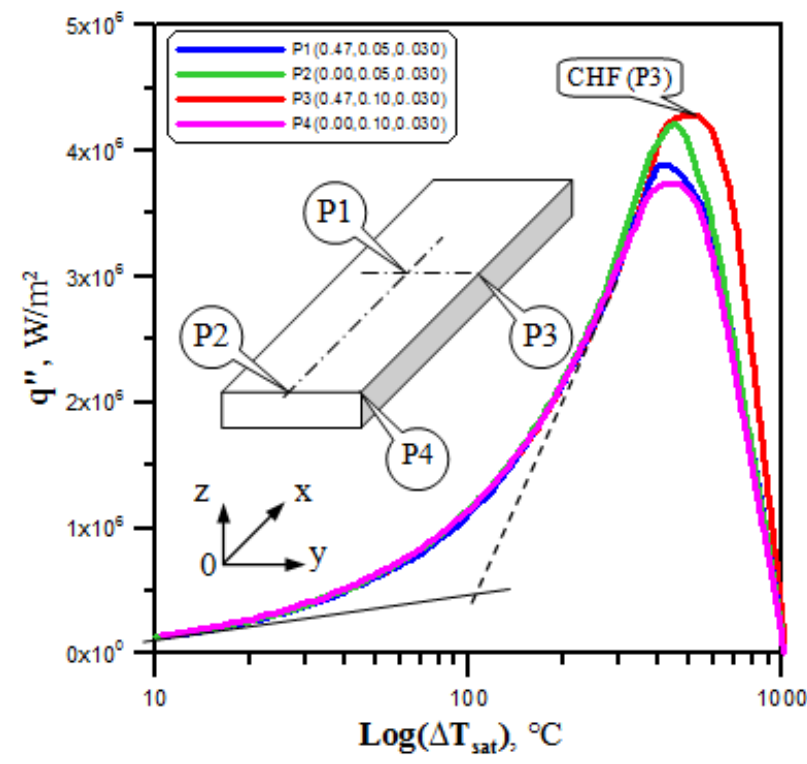

Figure 11. Heat flux for some points of the upper surface of slab

It is noted that in each of the sets of curves in figure 11 an enlargement that can distinguish the way in which the start of cooling can be occurring. The starting is irregular at first because of the complexity of boiling mechanisms, and then the progression seems to normal gaits, where a particular temperature distribution is observed for each group of curves assigning a specific evolution for this temperature.

The transition from the first to the second phase is due to heat transfer mechanisms of the two-phase cooling processes which distinguish completely from single-phase process. This transition is explained by the fact that very large variations in temperature and flux density at walls, lead to an increase in the transfer coefficient due particularly to the mechanisms of heat transfer in boiling.

\section{CONCLUSIONS}

Simulation of the cooling by water sprayed on a titanium static slab highly heated $\left(T_{0}=1104^{\circ} \mathrm{C}\right)$ was performed to predict distribution of the time dependent temperature field at any point of the slab. Usually, it is the materials of large consumption such as aluminum alloys, magnesium, steel or cast-iron alloys which are most studied. In our case it is Titanium which has become increasingly popular and the more used in recent years, by seeing extended its applications in field of nuclear energy, aerospace, medicine and household equipments. The main qualities of this material lie in its lightness, its rigidity and ability to withstand severe mechanical and thermal stresses. Its qualities are best than 
stainless steel and other steel materials, however, its flaw for its economy and availability. Intense heat extraction by water spraying, primarily, through the upper face of the slab and also from the other free outer faces decreases the temperature over time. This extraction cools the slab, first, along uniform isosurfaces at same temperatures evolving continually down, then the external environment, in interaction with the faces to the free sides of the slab to exchange heat with weaker intensity than that of the surface exposed to the spray.

Thermophysical properties of titanium are changed under the conditions of the accelerated cooling for the elevated temperatures, while these ones, at this level, modifies little the microscopic behavior, and therefore, the micrographic structure of material and the properties become nonlinear and varies in function of temperature over time. The complexity of the process of spray cooling has led to a significant disagreement with the mechanisms of basics heat transfer. This pushes to more research on numerical and experimental plans to reach at a more complete theory of the process.

Simulation results of temperature distribution are similar to the simulation of heat transfer of quenching; this implies that the basics of considered analysis method of the simulation are to be correct. Cooling rates at the surface and inside the body are markedly different. Moreover, they are influenced by temperature dependence of heat transfer coefficient and thermal conductivity of the material.

\section{REFERENCES}

[1] Gonzalez, M., Goldschmit, M.B., Assanelli, A.P., Berdaguer, E.F., and Dvorkin, E.N. (2003). Modeling of the solidification process in a continuous casting installation for steel slabs. Metallurgical and Materials $\begin{array}{llll}\text { Transactions } & \text { B, 34(4): 455-473. }\end{array}$ http://doi.org/10.1007/s11663-003-0072-3

[2] Komínek, J., Pohanka, M., Ondroušková, J. (2013). Determination of temperature dependent cooling intensity for the simulation of in-line heat treatment. Proceedings of Metal, 68-73. http://metal2013.tanger.cz/files/proceedings/12/reports/ 1513.pdf.

[3] Li, D., Wells, M.A., Cockcroft, S.L., Caron, E. (2007). Effect of Sample Start Temperature during Transient Boiling Water Heat Transfer. Metallurgical and Materials Transactions B, 38(6): 901-910. http://doi.org/10.1007/s11663-007-9091-9

[4] Sengupta, J., Thomas, B.G., Wells, M.A. (2004). Understanding the role water-cooling plays during continuous casting of steel and aluminum alloys. In Conference Proceedings of M\&ST, pp. 179-193. http://digital.library.aist.org/pages/PR-022-179.htm.

[5] Elguerri, M., Thesis, D. (2014). Hydrodynamic aspects during an overlapping water jets under spray nozzles and influences on the intensity of thermal transfer. Department of Mechanical Engineering, University of Sciences and Technology of Oran, Algeria. http://www.univ-

usto.dz/theses_en_ligne/doc_num.php?explnum_id=225 9.

[6] Kotrbáček, P., Horský, J., Raudenský, M., Pohanka, M. (2004). Influence of parameters of hydraulic descaling on temperature losses and surface quality of rolled material. Metal forming, $\quad$ pp. $367-370$.

http://www.heatlab.cz/uploads/download/Descaling/Des caling MetalForming2004.pdf.

[7] Mzad, H., Elguerri, M. (2012). Simulation of twin overlapping sprays underneath hydraulic atomizers: influence of spray hydrodynamic parameters. Atomization and Sprays, 22(5): 447-460. http://doi.org/10.1615/AtomizSpr.2012006076

[8] Xie, B.C., Wang, Y.K., Wang, Z.L., Zhao, W.S. (2011). Numerical simulation of titanium alloy machining in electric discharge machining process. Transactions of Nonferrous Metals Society of China, 21: s434-s439. http://doi.org/10.1016/S1003-6326(11)61620-8

[9] Zhang, F., Quan, Y., Reich, M., Kessler, O., Burkel, E. (2013). Sintering and heat treatment of titanium alloys by pulsed electric current sintering. Sintering Applications, pp. 259-283. http://doi.org/10.5772/53705

[10] Umezawa, O., Ishikawa, K. (1992). Electrical and thermal conductivities and magnetization of some austenitic steels, titanium and titanium alloys at cryogenic temperatures. Cryogenics, 32(10): 873-880. http://doi.org/10.1016/0011-2275(92)90353-C

[11] Taler, J., Duda, P. (2010). Solving direct and inverse heat conduction problems. Springer Science \& Business Media. http://doi.org/10.1007/978-3-540-33471-2

[12] Li, H., Zhao, G., He, L., Mo, Y. (2009). Solution of nonlinear thermal transient problems by a new adaptive timestep method in quenching process. Applied mathematical modelling, $\quad 33(1)$ : https://doi.org/10.1016/j.apm.2007.11.004

[13] Bratuta, E.G., Ivanowsky, A.Y. (1982). Intensification of heat and mass transfer during cooling by dispersed fluids. Energa-Machinotroen1a, 33: 98-101.

[14] Mzad, H., Tebbal, M. (2009). Thermal diagnostics of highly heated surfaces using water-spray cooling. Heat and mass transfer, 45(3): 287. https://doi.org/10.1007/s00231-008-0431-3

[15] Liscic, B., Tensi, H.M., Canale, L.C.F., and Totten, G.E. (2010). Quenching Theory \& Technology. Second Edition, CRC Press, Taylor \& Francis.

[16] Deiters, T.A., Mudawar, I. (1989). Optimization of spray quenching for aluminum extrusion, forging, or continuous casting. Journal of Heat Treating, 7(1): 9-18. https://doi.org/10.1007/BF02833183

[17] Chen, J., Tong, L., Wei, J., Sun, D. (2008). Numerical investigation on multiphase coupling heat conduction with subcooling boiling boundary conditions and effect of shape during quenching process. Journal of Materials Processing Technology, 203(1-3): 86-94. https://doi.org/10.1016/j.jmatprotec.2007.09.042

[18] Frkanova, K., Lapin, J. (2012). Relationship between microstructure and cooling rate in air-hardenable TiAlbased alloy. Proceedings of the METAL.

\section{NOMENCLATURE}

$C$

S

$T$

$X, Y, Z$

$g$

$h$

$n$

$q^{\prime \prime}$ specific heat, $\mathrm{kJ} \mathrm{kg}^{-1} \cdot \mathrm{K}^{-1}$

surface, $\mathrm{mm}^{2}$

temperature, ${ }^{\circ} \mathrm{C}$

dimension of the slab, $\mathrm{mm}$

dispersion, $\mathrm{mm}^{3} \cdot \mathrm{s}^{-1} \cdot \mathrm{mm}^{-2}$

convection coefficient, W. $\mathrm{m}^{-2} \cdot \mathrm{K}^{-1}$

normal vector

heat flux, W.m-2 


$\begin{array}{ll}t & \text { time, } \mathrm{s} \\ x, y, z & \text { Cartesian's coordinates, } \mathrm{mm}\end{array}$

\section{Greek symbols}

$\alpha$
$\varepsilon$
$\varphi$
$\lambda$
$\rho$
$\sigma$

\section{Subscripts}

$\begin{array}{ll}\text { Leid } & \text { Leidenfrost } \\ a & \text { air } \\ a m b & \text { ambient } \\ b & \text { boiling } \\ \text { conv } & \text { convection } \\ \text { inf } & \text { inferior } \\ p & \text { pressure } \\ \text { rad } & \text { radiation } \\ \text { sat } & \text { saturation } \\ \text { spr } & \text { spray } \\ w & \text { wall } \\ x, y, z & \text { direction } \\ 1,2 & \text { nozzle }\end{array}$

two-phase 